Int. J. Electrochem. Sci., 12 (2017) $3231-3240$

\title{
Highly Sensitive Voltammetric Sensor for Determination of Ascorbic Acid Using Graphite Screen Printed Electrode Modified with $\mathrm{ZnO} / \mathrm{Al}_{2} \mathrm{O}_{3}$ Nanocomposite
}

\author{
Mohammad Reza Ganjali ${ }^{1,2, *}$, Fariba Garkani Nejad ${ }^{3}, H_{\text {Hadi Beitollahi }}^{4}$, \\ Shohreh Jahani ${ }^{4}$, Morteza Rezapour ${ }^{5}$, Bagher Larijani ${ }^{6}$ \\ ${ }^{1}$ Center of Excellence in Electrochemistry, University of Tehran, Tehran, Iran \\ ${ }^{2}$ Biosensor Research Center, Endocrinology \& Metabolism Molecular-Cellular Sciences Institute, \\ Tehran University of Medical Sciences, Tehran, Iran \\ ${ }^{3}$ Department of Chemistry, Graduate University of Advanced Technology, Kerman, Iran \\ ${ }^{4}$ Environment Department, Institute of Science and High Technology and Environmental \\ Sciences, Graduate University of Advanced Technology, Kerman, Iran \\ ${ }^{5}$ IP Department, Research Institute of the Petroleum Industry (RIPI), P.O. Box 14665-137, Tehran, \\ Iran \\ ${ }^{6}$ Diabetes Research Center, Endocrinology \& Metabolism Clinical Sciences Institute, Tehran \\ University of Medical Sciences, Tehran, Iran \\ "E-mail: ganjali@khayam.ut.ac.ir
}

doi: $10.20964 / 2017.04 .07$

Received: 31 December 2016 / Accepted: 5 February 2017 / Published: 12 March 2017

\begin{abstract}
A sensitive and selective voltammetric sensor based on graphite screen printed electrode modified by $\mathrm{ZnO} / \mathrm{Al}_{2} \mathrm{O}_{3}$ nanocomposite for the detection of ascorbic acid has been successfully developed. The electrochemical behavior of prepared electrode for the determination of ascorbic acid was systematically investigated by cyclic voltammetry (CV) and differential pulse voltammetry (DPV). Under optimum conditions, the modified electrode exhibits linear responses to ascorbic acid in the ranges $1.0-100 \mu \mathrm{M}$, with detection limits $(\mathrm{S} / \mathrm{N}=3)$ calculated to be $0.6 \mu \mathrm{M}$. Finally, the developed sensor was successfully applied to the detection of ascorbic in real samples.
\end{abstract}

Keywords: Ascorbic acid; $\mathrm{ZnO} / \mathrm{Al}_{2} \mathrm{O}_{3}$ nanocomposite; Graphite screen printed electrode; voltammetry

\section{FULL TEXT}

(C) 2017 The Authors. Published by ESG (www.electrochemsci.org). This article is an open access article distributed under the terms and conditions of the Creative Commons Attribution license (http://creativecommons.org/licenses/by/4.0/). 